\title{
An automatic forest fires identification methodology using FY3A/B VIRR images
}

\author{
X. L. Qin ${ }^{1}$, Z. H. Zhang ${ }^{2}$, H. Yan ${ }^{2}$ \& X. Zhu \\ ${ }^{1}$ Research Institute of Forest Resource Information Techniques, \\ $C A F$, Beijing, China \\ ${ }^{2}$ State Laboratory for Remote Sensing and Information Techniques, \\ $C A F$, Beijing, China \\ ${ }^{3}$ Information Center of Forest Prediction and Monitoring, \\ State Forestry Administration, Beijing, China
}

\begin{abstract}
FengYun-3 (FY-3) is the second generation Polar Orbiting Meteorological Satellite Series of Chinese meteorological satellite. FY3A and FY3B were launched in the year 2008 and the year 2010 respectively. The Visible and Infrared Radiometer (VIRR) carried by FY3A/B (FY3A/B-VIRR), which spatial resolution is 1,100 meter at nadir and saturation temperature is more than $350 \mathrm{k}$ in central wavelength at $3.74 \mu \mathrm{m}$ channel. Based on the analyzing results of related bands of FY3A/B-VIRR by using typical samples, the algorithm applies dynamic thresholds to fire identification according to the character of FY3A/B VIRR images. The automatic forest fire identification program has been developed and integrated the background GIS data in IDL language. At the same time, the methodology and identification results have been validated by selecting forest fires which have taken place in the northeast or south forest region of China in nearly four years. The validation results showed that the commission is more than $90 \%$ and the average omission is less than $10 \%$. So, the fire identification methodology can be satisfied regarding the need for the forest fire identification operation in China.

Keywords: FY 3A/B-VIRR image, forest fire, remote sensing technique.
\end{abstract}




\section{Introduction}

Forest fire is a prominent global phenomenon, which not only destroys natural vegetation, but also poses enormous danger to wildlife as well as to human life and property. In addition, biomass burning by fires has been identified as a significant source of aerosols, carbon fluxes, and trace gases, which pollute the atmosphere and contribute to radiative forcing responsible for global climate change [1]. Many forest fires have taken place every year in China. The average forest fire frequency is over 10,000 times and the average damaged forest area is about 800,000 ha from year 1950 to 2010 . Forest fire has aroused extensive attention to Chinese government.

Timely and accurate detection of fires has become an issue of considerable importance. Various international organizations, such as the International Geosphere and Biosphere Program (IGBP) and Global Fire Monitoring Center (GFMC), have recognized the need for fire detection and monitoring using the high temporal and low spatial resolution satellite images at a global region [2]. Space-borne fire detection has been a topic of intensive research since the early 1980s. Much of the work has concentrated on fire monitoring methodology or estimation of atmospheric emissions from fires. There are many algorithms by using Advanced Very High Resolution Radiometer (AVHRR) data to detect fires [3-6]. From year 2000, the Moderate Resolution Imaging Spectroradiometer (MODIS) which carried on both the Terra and Aqua satellite has been broadly used for fire detection [7-11]. At the same time, many scientists have used the Along Track Scanning 1(ATSR-1) launched on ERS-1 in July 1991, ATSR-2 launched on ERS-2 in April 1995, and the Advanced Along Track Scanning Radiometer (AATSR) launched on ENVISAT in March 2002 to monitor fire [12-16]. The FengYun-3 (FY-3) series are the second generation of Chinese polar-orbiting meteorological satellites (following on of FY-1 series). Key aspects of the FY-3 satellite series include collecting atmospheric data for intermediate-term and long-term weather forecasting and global climate research. FY 3A and FY 3B were launched in the year 2008 and the year 2010 respectively. The Visible and Infrared Radiometer (VIRR) carried by FY3A/B (FY3A/B-VIRR), which spatial resolution is 1,100 meter at nadir and saturation temperature is $350 \mathrm{k}$ in central wavelength at $3.74 \mu \mathrm{m}$ and $330 \mathrm{k}$ at $10.8 \mu \mathrm{m}$. The saturation temperature of $3.74 \mu \mathrm{m}$ of $\mathrm{FY} 3 \mathrm{~A} / \mathrm{B}$ VIRR is higher than that of NOAA/AVHRR. It supplies a useful instrument for Chinese forest fire monitoring.

\section{Study area and dataset}

\subsection{Study area}

The country of China has been selected as the study area. It locates between $73^{\circ} 40^{\prime} \mathrm{E}$ to $135^{\circ} 2^{\prime} 30^{\prime \prime} \mathrm{E}$ and $3^{\circ} 52^{\prime} \mathrm{N}$ to $53^{\circ} 33^{\prime} \mathrm{N}$. The climate includes coldtemperate, warm-temperate, temperate, sub-tropical and tropical zone from the Northeast to the South of China. 
The vegetation types are more than 2,000 dominants of communities in China. The results of the $7^{\text {th }}$ Chinese national forest resources inventory showed that the forest area was about 195.5 million ha and the forest coverage was $20.36 \%$. The northeast forest region is the first of five important forest regions of China. Many large forest fires have taken place in this region, such as the famous large forest fire which took place in 1987. The southwest forest region is the second of five important forest regions of China. The frequency of forest fires is the largest compared to other regions in China every year.

\subsection{Dataset}

The geolocated and calibrated FY3A/B VIRR L1B images have been used for studying the forest fires identification algorithm. The images have been supplied by the National Satellite Meteorological Center of Chinese Meteorological Administration. The instrument includes 10 channels in the spectral range of $0.43-12.5 \mu \mathrm{m}$. The spatial resolution at nadir is 1,100 meter on a swath of 2,800 $\mathrm{km}\left(\mathrm{FOV}= \pm 55.4^{\circ}\right)$. The performance characteristics of VIRR instrument are shown in tab. 1.

Table 1: $\quad$ Performance characteristics of VIRR.

\begin{tabular}{|c|c|c|c|}
\hline $\begin{array}{c}\text { Channel } \\
\text { Number }\end{array}$ & $\begin{array}{c}\text { Spectral range } \\
(\mu \mathrm{m})\end{array}$ & $\begin{array}{c}\text { Noise equivalent reflectance } \\
\text { or NE } \Delta \mathrm{T}(\text { at } 300 \mathrm{~K})\end{array}$ & $\begin{array}{c}\text { Dynamic range } \\
(\% \text { or K })\end{array}$ \\
\hline 1 & $0.58-0.68$ & $0.1 \%$ & $0-100 \%$ \\
\hline 2 & $0.84-0.89$ & $0.1 \%$ & $0-100 \%$ \\
\hline 3 & $3.55-3.93$ & $0.3 \mathrm{k}-0.4 \mathrm{k}$ & $180-350 \mathrm{k}$ \\
\hline 4 & $10.3-11.3$ & $0.2 \mathrm{k}$ & $180-330 \mathrm{k}$ \\
\hline 5 & $11.5-12.5$ & $0.2 \mathrm{k}$ & $180-330 \mathrm{k}$ \\
\hline 6 & $1.55-1.64$ & $0.15 \%$ & $0-90 \%$ \\
\hline 7 & $0.43-0.48$ & $0.05 \%$ & $0-50 \%$ \\
\hline 8 & $0.48-0.53$ & $0.05 \%$ & $0-50 \%$ \\
\hline 9 & $0.53-0.58$ & $0.05 \%$ & $0-50 \%$ \\
\hline 10 & $1.325-1.395$ & $0.19 \%$ & $0-90 \%$ \\
\hline
\end{tabular}

\section{Methodology}

\subsection{Data preprocessing}

The selected FY3A/3B VIRR L1B datasets, which formation recorded as HDF 5.0 , were pre-processed including physical value calculation from $\mathrm{DN}$ and geometrically processing using program. Then, the value of every band was converted to the reflectance (at the top of the atmosphere) or bright temperature, and exported as a Geo-tiff format. 


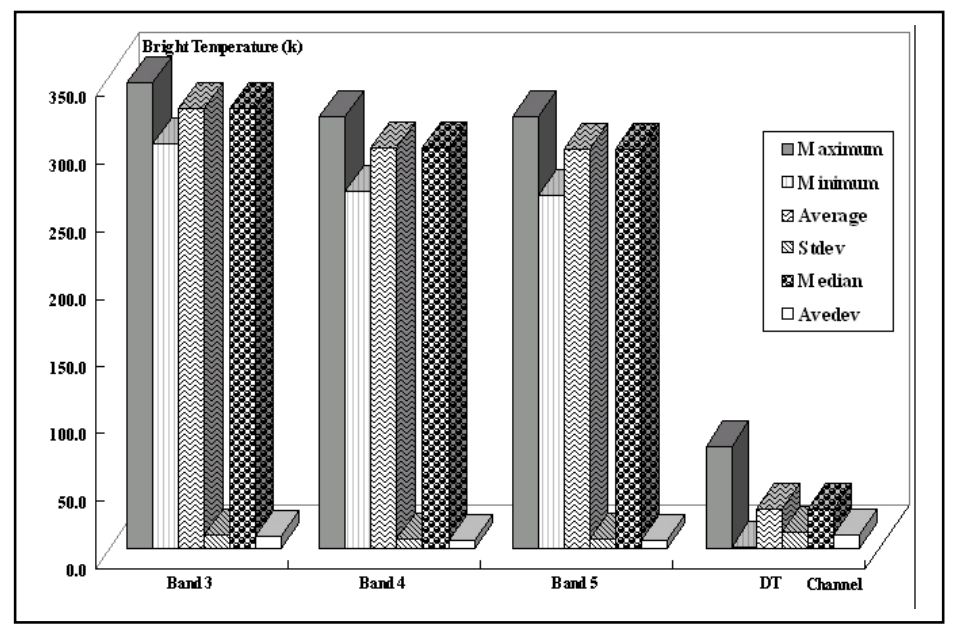

Figure 1: Bright temperature of fire in different bands in diurnal VIRR images.

\subsection{Data analysis}

In order to get the character of active forest fire in FY3A/B VIRR images, the statistic and spectral analysis of fire, smoke, burnt scar, vegetation, land, cloud, water and snow have been sampled from the selected VIRR L1B production images. The statistic analysis includes the average, maximum, minimum, standard deviation, and absolute deviation of reflectance or bright temperature. The statistics of the thermal values were analyzed according to the bright temperature in channels $3-5$ and the difference between channels 3 and 4 , distinguishing between night images and diurnal images, always on nonsaturated pixels. Besides, for diurnal images, the reflectance in channels $1,2,6$, $7,8,9$ and 10 were also analyzed with a view to using them for the filtering of false alarms. Part of the analysis results have been listed in figures 2 and 3 .

According to the analyzing results, the differences of these typical land cover have been found in different channels of VIRR images. So, the sensitive channels have been selected to identify forest fires.

\subsection{Algorithm}

The algorithm uses brightness temperatures derived from the channel 3 and the channel 4 of VIRR images, denoted by $\mathrm{T}_{4}$ and $\mathrm{T}_{11}$, respectively. Channel 5 is used for cloud masking; brightness temperatures for this channel are denoted by $\mathrm{T}_{12}$. The channel 1 (red), channel 2 (near infrared), and channel 10 (SWIR) are used to reject false alarms and mask clouds. Their reflectance is denoted by $R_{1}$ $R_{2}$ and $R_{10}$, respectively. The channel 6 (SWIR) is used to reject sun glint, waterinduced false alarms; the reflectance of this channel is denoted by $R_{6}$. A summary of all VIRR channels used in the algorithm is shown in tab. 2 . 


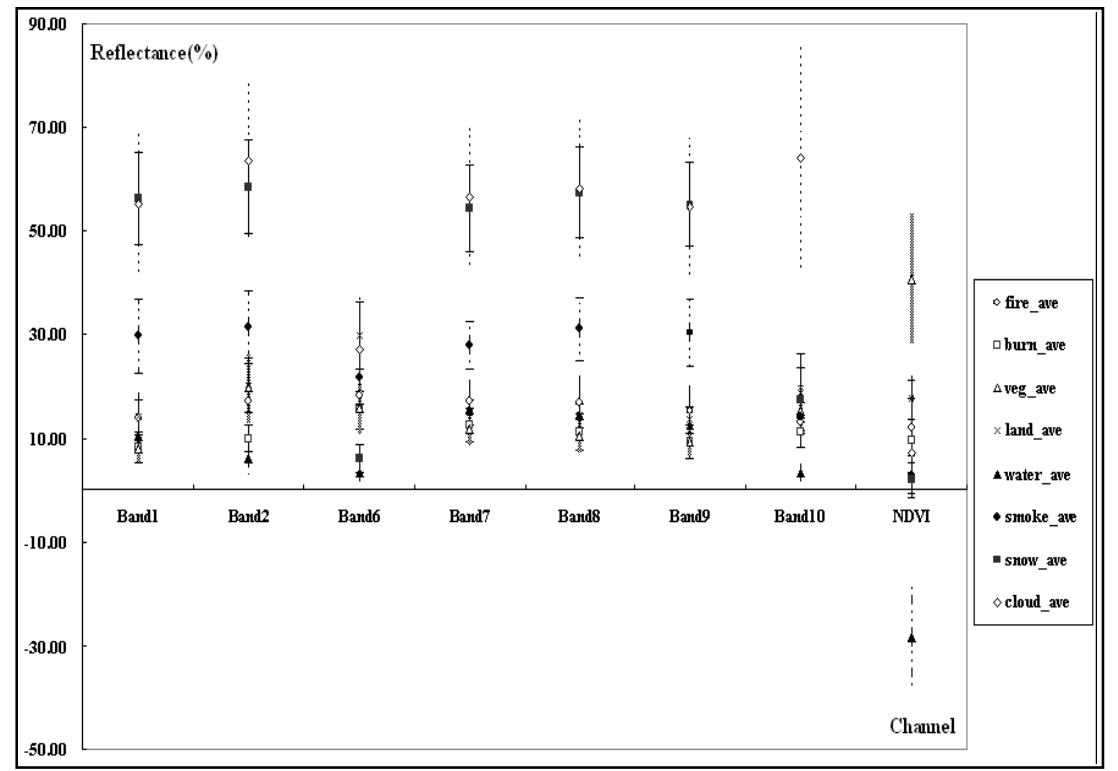

Figure 2: Average value and their standard deviation of typical and cover in diurnal VIRR images.

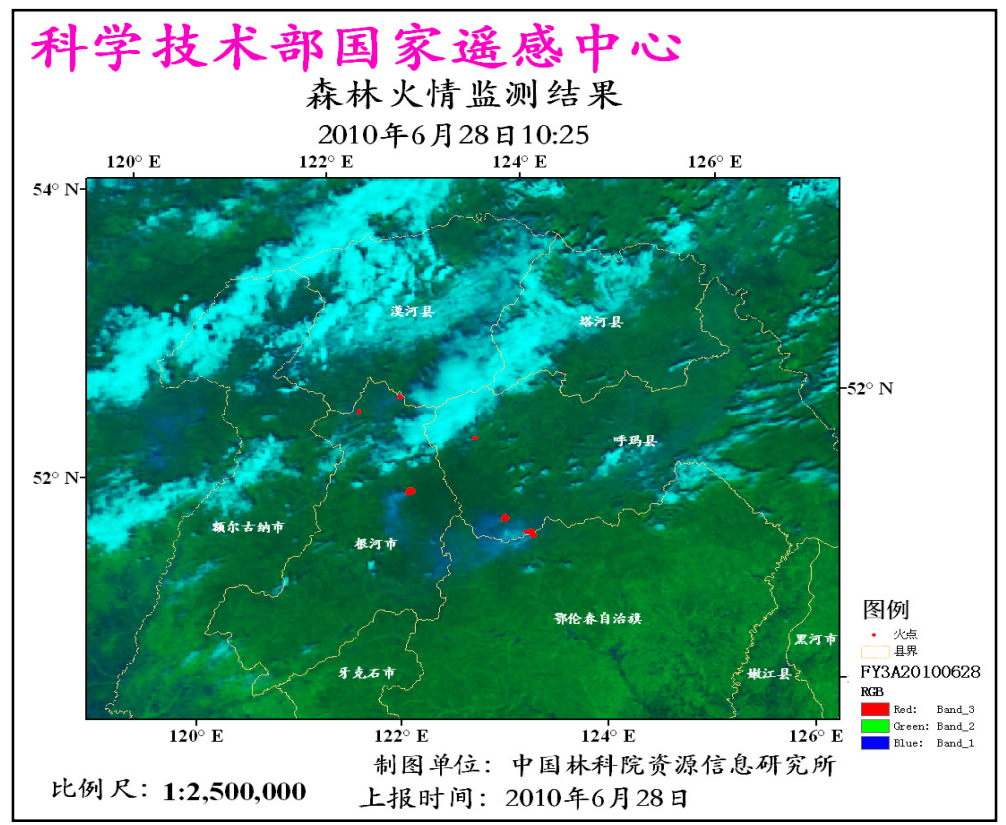

Figure 3: $\quad$ Result of forest fire identification using VIRR images. 
Table 2: $\quad$ The selected VIRR channel in detection algorithm.

\begin{tabular}{|c|c|c|}
\hline $\begin{array}{c}\text { Channel } \\
\text { Number }\end{array}$ & $\begin{array}{c}\text { Central wavelength } \\
(\mu \mathrm{m})\end{array}$ & Purpose \\
\hline 1 & 0.63 & $\begin{array}{r}\text { Cloud masking; Sun glint and coastal false } \\
\text { alarm rejection. }\end{array}$ \\
\hline 2 & 0.86 & $\begin{array}{c}\text { Cloud masking; Bright surface, sun glint, } \\
\text { and coastal false alarm rejection. }\end{array}$ \\
\hline 3 & 3.74 & Active fire detection \\
\hline 4 & 10.8 & Active fire detection \\
\hline 5 & 12.0 & Cloud masking \\
\hline 6 & 1.60 & Sun glint and coastal false alarm rejection \\
\hline 10 & 1.36 & Cloud masking; water masking \\
\hline
\end{tabular}

\subsubsection{Cloud masking}

Clouds in fire identification process using satellite images have two roles. One is reducing the active fire points when the cloud covers the fire. The other is increasing the false active fire points when the strong solar irradiation. Cloud detection was performed using a modification technique based on the methodology of Stroppiana et al. [17] in AVHRR-derived Global Fire Product.

Daytime pixels are considered to be cloud if one condition of the eqn (1), (2), (3), and (4) is satisfied:

$$
\begin{gathered}
\mathrm{R}_{1}+\mathrm{R}_{2}>90 \% \\
\mathrm{~T}_{12}<264 \mathrm{~K} \\
\left\{\begin{array}{l}
R_{1}+R_{2}>75 \% \\
T_{12}<285 k
\end{array}\right. \\
\mathrm{R}_{10}>40 \%
\end{gathered}
$$

Nighttime pixels are flagged as cloud if the eqn (2) condition is satisfied.

\subsubsection{Water masking}

Water pixels were identified using the $1.1 \mathrm{~km}$ prelaunch land $/ \mathrm{sea}$ mask contained in the VIRR geolocation product. Significant errors have been noted in this dataset. However, the values of daytime pixels belong to water in band 10 and NDVI are different with other bands. So, the water pixels of daytime images have been classified as water if one condition of the eqn (5) or (6) is satisfied:

$$
\begin{gathered}
\mathrm{R}_{10}<6 \% \\
\text { NDVI }<-15 \%
\end{gathered}
$$

\subsubsection{Fire identification algorithms}

A neighbor 'spilt windows' criterion identical method has been used for fire identification. The neighbor 'spilt windows' criterion identical method is widely used in fire detection of satellite image (Kaufman and Justice [7] and Kaufman et al. [8]; Justice et al. [9]; Giglio et al. [11]). Here, a 'spilt window' (from $3 \times 3$ to 
$11 \times 11$ pixels) has been used to identify fire and a series of tests are used to perform fire detection. These look for the characteristic signature of an active fire in which both the brightness temperature of band 3,4 and the difference of bands 3 and 4, depart substantially from that of the non-fire background. Relative thresholds are adjusted based on the natural variability of the background. The conditional tests are listed from eqns. (7)-(10).

$$
\begin{gathered}
D T>\overline{D T} b+4.0 \Delta D T_{b} \\
T_{4}>\bar{T}_{4 b}+3.0 \Delta T_{4 b} \\
T_{11}>\bar{T}_{11 b}+\Delta T_{11 b}-4.0 k \\
2.0 \%<N D V I<23.0 \%
\end{gathered}
$$

where: DT is bright temperature difference of $3.74 \mu \mathrm{m}$ and $11 \mu \mathrm{m}$;

$\Delta D T_{b}$ is the standard deviation of background pixels of DT

$\overline{D T}_{b}$ is the mean of background pixels of DT

$\bar{T}_{4 b}$ is the mean of background pixels at $3.7 \mu \mathrm{m}$ band

$\Delta T_{4 b}$ is the standard deviation of background pixels at $3.7 \mu \mathrm{m}$ band

$\bar{T}_{11 b}$ is the mean of background pixels in $11 \mu \mathrm{m}$ band

$\Delta T_{11 b}$ is the standard deviation of background pixels at $11 \mu \mathrm{m}$ band

NDVI is the Normal Difference Vegetation Index.

A pixel in daytime will be flagged as fire point if it satisfies eqns. (7)-(10). However, a pixel in night-time just need satisfy eqns. (7), (8) and (9).

\subsubsection{False alarm rejection}

To the diurnal image, false fire alarm can be caused by strong solar, desert boundary and coastal. The 1:1,000,000 scale vegetation distribution map has been used to identify the type of land cover in this experiment. So, we just consider the false fire caused by strong solar in diurnal images. A pixel in daytime will be eliminated as sun false fire point from fire point if its sun glint satisfies eqn. (10).

$$
\left\{\begin{array}{l}
R_{1}>20 \% \\
R_{2}>5 \% \\
\theta<40^{\circ}
\end{array}\right.
$$

where: $\theta$ is the sun glint.

The sun glint was calculated by using the methodology as Kaufman et al. [7] as eqn (11).

$$
\operatorname{Cos} \theta=\cos \theta_{v} \cos \theta_{\mathrm{s}}-\sin \theta_{v} \sin \theta_{\mathrm{s}} \cos \Phi
$$


Here, $\theta_{v}$ and $\theta_{\mathrm{s}}$ are the view and solar zenith angles, respectively, and $\Phi$ is the relative azimuth angle.

\section{Results and validation}

\subsection{Results}

The fire identification methods have been used in Chinese forest fire monitoring. Fig. 3 and tab. 3 are the results of fire identification.

Table 3: $\quad$ Records of forest fire identification using VIRR images.

\begin{tabular}{|c|c|c|c|c|c|c|c|c|c|c|c|}
\hline Longitude & Latitude & Ref1 & Ref2 & T4 & T12 & Area(ha) & Date & Time & Satellite & Country & Types \\
\hline 122.368271 & 51.675926 & 19.06 & 23.65 & 344.81 & 305.57 & 341.90 & 20100628 & $2: 25$ & FY3A_VIRR & $\begin{array}{l}\text { Genhe, Inner } \\
\text { Mongolia }\end{array}$ & Grass \\
\hline 122.384087 & 51.674412 & 15.37 & 20.42 & 343.95 & 306.46 & 339.90 & 20100628 & $2: 25$ & FY3A_VIRR & $\begin{array}{l}\text { Genhe, Inner } \\
\text { Mongolia }\end{array}$ & fixed fores \\
\hline 122.400314 & 51.672855 & 12.86 & 19.19 & 337.47 & 307.88 & 337.92 & 20100628 & $2: 25$ & FY3A_VIRR & $\begin{array}{c}\text { Genhe, Inner } \\
\text { Mongolia }\end{array}$ & Shrubs \\
\hline 122.416695 & 51.671280 & 10.05 & 22.72 & 333.21 & 305.21 & 335.96 & 20100628 & $2: 25$ & FY3A_VIRR & $\begin{array}{c}\text { Genhe, Inner } \\
\text { Mongolia }\end{array}$ & $\begin{array}{c}\text { Needleleaf } \\
\text { forests }\end{array}$ \\
\hline 123.306114 & 51.441746 & 11.61 & 24.73 & 345.06 & 304.79 & 245.54 & 20100628 & $2: 25$ & FY3A_VIRR & $\begin{array}{c}\text { Huma, } \\
\text { Heilongjiang }\end{array}$ & $\begin{array}{c}\begin{array}{c}\text { Needleleaf } \\
\text { forests }\end{array} \\
\end{array}$ \\
\hline 123.302185 & 51.432137 & 13.37 & 20.91 & 345.33 & 306.85 & 245.54 & 20100628 & $2: 25$ & FY3A_VIRR & $\begin{array}{c}\text { Huma, } \\
\text { Heilongjiang }\end{array}$ & $\begin{array}{c}\text { Needleleaf } \\
\text { forests }\end{array}$ \\
\hline 123.316292 & 51.430664 & 11.75 & 24.26 & 328.65 & 302.06 & 244.48 & 20100628 & $2: 25$ & FY3A_VIRR & $\begin{array}{c}\text { Huma, } \\
\text { Heilongjiang }\end{array}$ & $\begin{array}{c}\text { Needleleaf } \\
\text { forests }\end{array}$ \\
\hline 123.284515 & 51.423981 & 19.67 & 22.43 & 344.11 & 305.60 & 246.62 & 20100628 & $2: 25$ & FY3A_VIRR & $\begin{array}{c}\text { Huma, } \\
\text { Heilongjiang }\end{array}$ & lixed fores \\
\hline 123.312706 & 51.421036 & 13.22 & 24.72 & 345.30 & 305.15 & 244.48 & 20100628 & $2: 25$ & FY3A_VIRR & $\begin{array}{c}\text { Huma, } \\
\text { Heilongjiang }\end{array}$ & fixed fores \\
\hline 123.327263 & 51.419510 & 12.04 & 25.94 & 329.79 & 301.70 & 243.42 & 20100628 & $2: 25$ & FY3A_VIRR & $\begin{array}{c}\text { Huma, } \\
\text { Heilongjiang }\end{array}$ & $\begin{array}{c}\text { Needleleaf } \\
\text { forests }\end{array}$ \\
\hline 123.280937 & 51.414253 & 17.03 & 26.09 & 327.14 & 302.25 & 246.62 & 20100628 & $2: 25$ & FY3A_VIRR & $\begin{array}{c}\text { Huma, } \\
\text { Heilongjiang }\end{array}$ & fixed fores \\
\hline 123.295044 & 51.412781 & 14.39 & 24.87 & 342.45 & 306.94 & 245.54 & 20100628 & $2: 25$ & FY3A_VIRR & $\begin{array}{c}\text { Huma, } \\
\text { Heilongjiang }\end{array}$ & Grass \\
\hline 123.309006 & 51.411320 & 12.78 & 25.79 & 340.66 & 302.34 & 244.48 & 20100628 & $2: 25$ & FY3A_VIRR & $\begin{array}{c}\text { Huma, } \\
\text { Heilongjiang }\end{array}$ & lixed fores \\
\hline 123.543861 & 51.315868 & 12.75 & 24.67 & 330.97 & 303.94 & 226.88 & 20100628 & $2: 25$ & FY3A_VIRR & $\begin{array}{c}\text { Huma, } \\
\text { Heilongiiang }\end{array}$ & Grass \\
\hline 123.484764 & 51.312355 & 27.69 & 28.94 & 326.82 & 302.77 & 230.55 & 20100628 & $2: 25$ & FY3A_VIRR & $\begin{array}{c}\text { Huma, } \\
\text { Heilongiiang }\end{array}$ & $\begin{array}{c}\begin{array}{c}\text { Broadleaf } \\
\text { forests }\end{array} \\
\end{array}$ \\
\hline 123.498596 & 51.310883 & 23.30 & 26.66 & 328.60 & 302.31 & 229.62 & 20100628 & $2: 25$ & FY3A_VIRR & $\begin{array}{c}\text { Huma, } \\
\text { Heilongjiang }\end{array}$ & $\begin{array}{c}\begin{array}{c}\text { Needleleaf } \\
\text { forests }\end{array} \\
\end{array}$ \\
\hline 123.525826 & 51.307976 & 18.02 & 21.63 & 328.85 & 305.57 & 227.78 & 20100628 & $2: 25$ & FY3A_VIRR & $\begin{array}{c}\text { Huma, } \\
\text { Heilongjiang }\end{array}$ & $\begin{array}{c}\begin{array}{c}\text { Needleleaf } \\
\text { forests }\end{array} \\
\end{array}$ \\
\hline 123.540291 & 51.306427 & 14.65 & 19.34 & 342.72 & 310.59 & 226.88 & 20100628 & $2: 25$ & FY3A_VIRR & $\begin{array}{c}\text { Huma, } \\
\text { Heilongjiang }\end{array}$ & Grass \\
\hline
\end{tabular}

\subsection{Validation}

We had put the active fire points on the geometrical correction VIRR images, and decided whether they are fires or false fires.

Twelve forest fires have been selected to test the fire detection methodology in this time. Here, we use the hitting precision and missing precision to test the method. The hitting precision is calculated by using eqn (12). The missing precision is calculated by using eqn (13). Part of results has been listed in tab. 4 . 


$$
p=\frac{M}{N} * 100 \%
$$

where: $\mathrm{P}$ is hitting precision; $\mathrm{M}$ is the number of pixels; $\mathrm{N}$ is the number of fire pixels.

$$
\mathrm{E}=100-\mathrm{P}
$$

where: $\mathrm{E}$ is missing precision;

Table 4: $\quad$ Results of validation.

\begin{tabular}{|c|c|c|c|c|c|c|}
\hline Date & Location & $\begin{array}{c}\text { Number of } \\
\text { fire pixel }\end{array}$ & M & N-M & $\begin{array}{c}\text { P } \\
\mathbf{( \% )}\end{array}$ & $\begin{array}{c}\mathrm{E} \\
(\mathbf{\%})\end{array}$ \\
\hline Apr. 29, 2009 & Xunke, Heilong & 87 & 79 & 8 & 90.8 & 9.2 \\
\hline May 3, 2009 & Xunke, Heilong & 36 & 32 & 4 & 91.6 & 8.4 \\
\hline May 11, 2009 & Xunke, Heilong & 5 & 5 & 0 & 100.0 & 0.0 \\
\hline Oct. 4, 2009 & Lansan, Hunan & 3 & 3 & 0 & 100.0 & 0.0 \\
\hline Oct. 4, 2009 & Yudu, Jiangxi & 5 & 5 & 0 & 100.0 & 0.0 \\
\hline June 28, 2010 & $\begin{array}{c}\text { Genhe, Inner } \\
\text { Mognia }\end{array}$ & 18 & 16 & 2 & 88.9 & 11.1 \\
\hline June 28, 2010 & $\begin{array}{c}\text { Huma, } \\
\text { Heilongjiang }\end{array}$ & 27 & 24 & 3 & 88.9 & 11.1 \\
\hline Feb. 10, 2010 & Tianlin, Guangxi & 12 & 11 & 1 & 91.6 & 0.0 \\
\hline Feb. 27, 2011 & Pingtang, Guizhou & 2 & 2 & 0 & 100.0 & 0.0 \\
\hline Feb. 27, 2011 & Ganzee, Sichuan & 5 & 4 & 1 & 80.0 & 20.0 \\
\hline Apr. 30, 2011 & Huguan, Shanxi & 41 & 38 & 3 & 92.7 & 7.3 \\
\hline Jan. 24, 2112 & Dali, Yunnan & 1 & 1 & 0 & 100.0 & 0.0 \\
\hline Total & & 242 & 220 & 22 & 90.9 & 9.1 \\
\hline
\end{tabular}

\section{Conclusions}

The forest fire identification methodology has been studied by using FY3A/BVIRR images in the experimental area. It shows that the FY3A/B-VIRR images are useful data for forest fire monitoring. They can give some fire information for fire prevention.

The relative threshold fire identification by using the bright temperature and reflectance of FY 3A/B VIRR images for the experiment area has been developed and validated in this time. From tab. 4, we can see all of the hitting precisions are more than $85 \%$. The average hitting precision is about $90 \%$. It shows that the methodology is viable. However, there are still missing some fire pixels in the validation area. In fact, the forest fires often take place during 10:00 am and 15:00 pm in China. At the same time, this study just has been validated by using part of FY 3A/B VIRR images. So, further study is needed to verify the algorithm of FY 3A/B VIRR whether it can satisfy the condition of national of 
China or global scale. In the future, there might be some parameters that needed to be considered in the model, adjustment and modification.

\section{Acknowledgements}

Thanks go to CMA/NSMC for supplying FY 3A/B VIRR L1B data for the study. The fund of this work has been supported by the Project E0305/1112/05, and MOST-ESA Cooperation Project 'Dragon Project (Dragon Proposal id 5258)'.

\section{References}

[1] Ichoku, C., Kaufman, Y. J. and Giglio, L., et al., Comparative analysis of daytime fire detection algorithms using AVHRR data for the 1995 fire season in Canada: perspective for MODIS, International Journal of Remote Sensing, 24(8), 1669-1690, 2003.

[2] Giglio, L., Kendall, J. D. and Justice, C. O., Evaluation of global fire detection algorithms using simulated AVHRR infrared data, International Journal of Remote Sensing, 20, 1947-1985, 1999.

[3] Dozier, J., A method for satellite identification of surface temperature fields of subpixel resolution, Remote Sensing of Environment, 11, 221-229, 1981.

[4] Fang, M. and Huang, W., Tracking the Indonesian forest fire using NOAA/AVHRR images, International Journal of Remote Sensing, 19(3):387-390, 1998.

[5] Flasse, S. P. and Ceccato, P., A contextual algorithm for AVHRR fire detection, International Journal of Remote Sensing, 17, 419-424, 1996.

[6] Li, Z., Kaufman, Y. J. and Ichoku, C., A review of AVHRR-based active fire detection algorithms: Principles, limitations, and recommendations, In Global and Regional Vegetation Fire Monitoring from Space: Planning and coordinated international effort, edited by F. Ahern, J.G. Goldammer, and C. Justice (The Hague: SPB Academic Publishing), 199-225, 2001.

[7] Kaufman, Y. J., and Justice, C., Algorithm for remote sensing of tropospheric aerosol from MODIS. Algorithm Technical Background Document, 10, 1998.

[8] Kaufman, Y. J., Justice, C. O. and Flynn, L. P., et al., Potential global fire monitoring from EOS-MODIS, Journal of Geophysical Research, Vol. 103, 32215-32238, 1998.

[9] Justice, C. O., Giglio, L. and Korontzi, S., et al., The MODIS fire products, Remote Sensing of Environment, 83, 244- 262, 2002.

[10] Kaufman, Y. J., Ichoku, C. and Korontzi, S., et al., Fire and smoke observed from the Earth Observing System MODIS instrument-production and operational use, International Journal of Remote Sensing, Vol. 24(8), 1765-1781, 2003.

[11] Giglio, L., Descloitres, J., Justice, C. O. and Kaufman, Y. J., An Enhanced Contextual Fire Detection Algorithm for MODIS, Remote Sensing of Environment, 87: 273-282, 2003. 
[12] Andrew, B. (2002). The AATSR Handbook, Rutherford Appllet Laboratory, Chilton, 20 August.

[13] Kelhă, V., Rauste, Y. and Hăme, T., et al. (2003). Combining AVHRR and ATSR satellite sensor data for operational boreal forest fire detection, International Journal of Remote Sensing, 24(8), 1691-1708.

[14] Arino, O. and Rosaz, J., 1999, 1997 and 1998 world ATSR fire atlas using ERS-1 ATSR-2 data, Proceedings of the Joint Fire Science Conference, Boise, 15-17 June, 1999.

[15] Arino, O., and Rosaz, J., 2000, 1997 world ATSR fire atlas, IUFRO, Conference on Remote Sensing and Forest Monitoring, 1-3 June (Luxembourg: European Commission), 606-615,1999.

[16] Qin X. L., Li Z. Y. and Tian X., et al., Forest fires identification using AATSR and MODIS data, European Space Agency, (Special Publication), Sp611, 1:293-299,2006.

[17] Stroppiana, D., Pinnock, S., and Grégoire, J. M., The Global Fire Product: Daily fire occurrence from April 1992 to December 1993 derived from NOAA AVHRR data. International Journal of Remote Sensing, 21, 1279$1288,2000$. 